\title{
CLINICAL IMPACT OF MODIFIED LINGUAL SPLIT BONE TECHNIQUE USING PIEZOTOME ON POST-OPERATIVE SEQUELAE OF MANDIBULAR $3^{\text {rd }}$ MOLAR REMOVAL
}

\author{
Mohamed Zaghlool Amer
}

\begin{abstract}
Problem statement: Permanent nerve damage represented one of the most severe complications following third molar extractions. Such rate increases especially, following lingual split bone technique either during bone splitting or dissecting procedures. So, this study was directed to assess clinical impact of modified lingual split bone technique using piezotome versus conventional technique on postoperative sequelae following mandibular $3^{\text {rd }}$ molar removal.
\end{abstract}

Patient and Methods: Eighteen patients of comparable surgical difficulty of impacted lower third molar representing a common pool divided randomly into two uniform equal groups. The $1^{\text {st }}$ group contained nine patients subjected to tooth removal using conventional lingual split bone technique. While, the $2^{\text {nd }}$ group contained nine patients treated by modified lingual split bone technique using peizotome. After recording the operation time, all patients were assessed postoperatively for pain, trismus, swelling at the $2^{\text {nd }}$ and $7^{\text {th }}$ day. Neurosensory deficit/paraesthesiae was assesed either at 7, 15 and 30 postoperative days. Postoperative symptom severity (PoSSe) scale and prognosis score of healing were assessed at the $7^{\text {th }}$ postoperative day.

Results: Comparing both groups, a significant difference was recorded regarding to severity of pain after $48 \mathrm{~h}(\mathrm{P}=0.037)$. However, no significant difference was recorded among both groups with regard to severity of pain at $7^{\text {th }}$ day postoperatively $(\mathrm{P}=0.169)$. Regarding to recorded interincisal distance and sum of facial swelling, a clear detectable significant differences were recorded between both groups at the $2^{\text {nd }}$ and $7^{\text {th }}$ day of follow up ( $\mathrm{P}=0.009,0.005-0.001,0.001$ respectively). A statistical significant differences were recorded between both groups after 7 and 15 days of follow up $(\mathrm{p}=0.035)$ regarding to two point discrimination.

Conclusion: Although, a remarkable improvement in the postoperative sequelae associated with piezotome versus conventional lingual split bone technique. However, such technique sensitive maneuver related to operator experience and device adoption can lead to a significant prolonged operation time making a restrictive insult to achieve optimal clinical outcomes among oral surgeons.

KEYWORDS: Lingual Split Bone Technique- Piezotome- Mandibular $3^{\text {rd }}$ Molar

* Associate Professor of Oral \& Maxillofacial Surgery, Faculty of Dentistry, Mansoura University 


\section{INTRODUCTION}

Surgical removal of impacted lower third molar is considered as one of the most common routine operations in the oral cavity. ${ }^{1}$ The surgical extraction difficulty can be varied widely from relatively easy to extremely difficult depending on several factors including location, depth, angulations, and bone density. ${ }^{2}$ Postoperative pain, trismus and swelling are considered as a classic early reversible sequelae that influence the patients' quality of life. ${ }^{3,4}$

Basically, surgical removal of impacted mandibular third molar was carried either through using guttering technique by surgical bur or simplified lingual split bone technique. ${ }^{5}$ In general, simplified split bone technique is characterized by increased risk of lingual nerve injury and their possible association with excessive hemorrhage from lingual soft tissue in addition to liability of sublingual spaces infection with progression of edema in close proximity to the airway. ${ }^{5}$ Such increase in the risk of these complications can be attributed first, to lack of precise extension of intended directed fracture of the lingual wall associated with lingual split bone technique and second to dissecting process of broken lingual plate from the overlying mucoperiosteum. ${ }^{5}$

One of derivatives from the category of ultrasonic dental scalers is "Piezosurgery" device. It was first developed by Prof. Tomaso Vercellotti in the year 2004 and introduced in oral and craniomaxillofacial surgery using the benefit of oscillating force that allow surgeon to efficiently handle hard tissue including bone and dentine. ${ }^{6}$

Although, several advantages of ultrasonic surgery were accepted by oral and craniomaxillofacial surgeons; such as atrumatic and precise cutting during surgery, minimal bleeding of osteotomy site, ${ }^{7}$ soft tissue preservation ${ }^{8}$ as well as stimulating effects of bone healing. ${ }^{9}$ However, the most commonly directed criticism to ultrasonic surgery is time consuming beside its limited clinical benefit for the patient during daily routine oral surgery. ${ }^{10}$

Based on such debates, this study was directed to assess clinical impact that can be resulted from modified lingual split bone technique using piezotome versus conventional technique on postoperative sequelae following surgical removal of impacted mandibular third molar.

\section{PATIENTS AND METHODS}

Eighteen patients of comparable surgical difficulty of impacted lower third molar representing a common pool were divided randomly into two uniform equal groups. All patients were selected from oral surgery department, Faculty of Dentistry, Mansoura University. The $1^{\text {st }}$ group contained nine patients subjected to tooth removal using conventional lingual split bone technique. While, the $2^{\text {nd }}$ group contained nine patients treated with modification of lingual split bone technique using peizotome during removal of lingual plate. All patients included in this study were radiographed preoperatively using panoramic x ray film (Fig.1-a) with further utilization of cone beam computed tomography (CBCT) (Fig.1-c,d) in abnormally or deeply seated impacted lower third molar for proper evaluation of the surrounding osseous and related vital structures prior to application of the used surgical technique.

\section{Operative procedures}

All patients were instructed to apply Chlorohexidiene $0.12 \%$ mouth wash (Hexitol, Arab Drug Company, Cairo, A.R.E) for 1 min immediate preoperatively. The surgical technique was done under local anaesthesia (Mepivacaine $\mathrm{HCl} 2 \%$ with Levonordefrin 1:20.000. Alexandria Co. Egypt) using a standardized linear gingival incision on the alveolar ridge extended from retromolar region to second molar with a $1-\mathrm{cm}$ oblique incision in the buccal area opposite this tooth. 

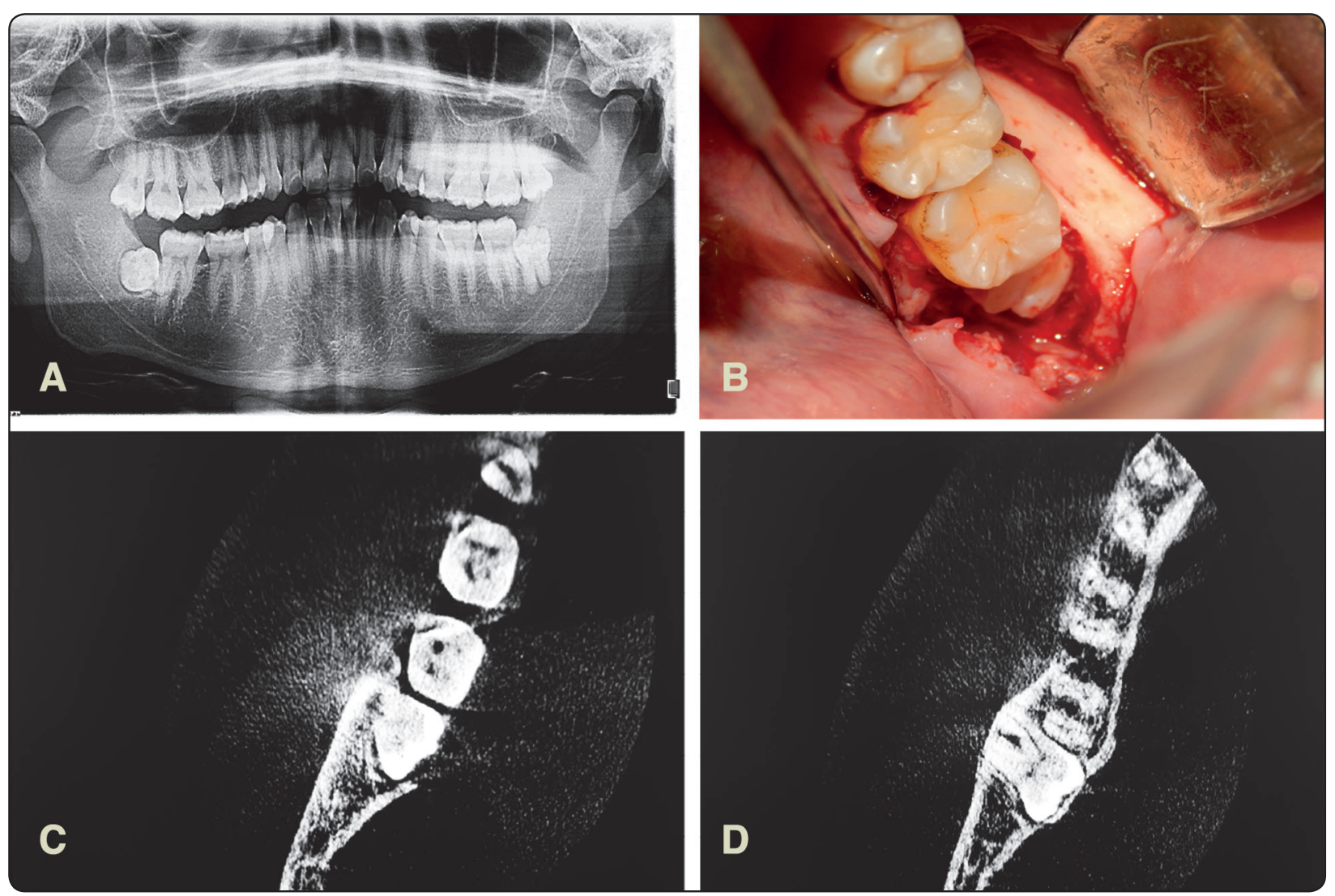

Fig. (1) A Showing a panoramic xray film revealing lingual deflection of impacted mandibular 3rd molar-B- Showing intraopertive exposure of lingually deflected and impacted mandibular 3rd molar C\&D Cross sectional image of CBCT revealing lingual deflection of impacted mandibular 3rd molar at variable depth.

Surgical removal of lower third molar was carried for patients included within $1^{\text {st }}$ group using conventional lingual split bone technique. Following proper elevation and retraction of buccal and lingual mucoperiosteal flap, removal of buccal bone using a horizontal cut after creating an initial vertical stopping cut was made. Then, a $45^{\circ}$ lingual split cut parallel to external oblique ridge was done. ${ }^{5}$ While, patients in $2^{\text {nd }}$ group, were subjected to application of piezotome (Ultra-Surgery Manufacture by Guilin WoodPecker Medical Instrument Co.- China) for removal of directed osteotomy through separating an adequate part of lingual plate by using tip US1 type comparable to those resulted from mallet driven chisel in the conventional lingual split bone technique in the $1^{\text {st }}$ group. An additional spatula tips UL1 \& UL5 were used to clean the produced surgical defect from any residue. The vibration frequency was maintained between 24 and $29.5 \mathrm{kHz}$ and the oscillation amplitude between 60 and 210 micrometer and power less than 80 Watts. Following tooth removal surgical site was irrigated using $0.9 \%$ physiologic saline. Then, mucoperiosteal flap was repositioned and sutured.

Postoperative medication was consisted of Augmentin 625mg (Amoxicillin+ Clavulanate potassium, GlaxoSmithKline S.A.E, El Salam City, Cairo,A.R.E) oral antibiotics every 8 hours for 7 days and Diclofenac Potassium (Oflam, Mepha Pharma Egypt S.A.E) 50mg tablets. Patients were instructed for maintaining optimal oral hygiene with Chlorohexidiene $\mathrm{HCl}$ 0.12\% (Hexitol, Arab Drug Company, Cairo, A.R.E). 
All patients were assessed postoperatively for pain, trismus, swelling at the $2^{\text {nd }}$ and $7^{\text {th }}$ day. Neurosensory deficit/paraesthesiae was assesed postoperatively at 7,15 and 30 days. Postoperative symptom severity (PoSSe) scale and prognosis score of healing were assessed at the $7^{\text {th }}$ postoperative day. Time of surgical procedures was taken from starting the incision till completion of wound suturing. ${ }^{10}$

\section{Pain and swelling assessment}

Patients were allowed to subjectively rate the pain intensity according to Visual analogue scale (VAS) on a brightness-coded color scale ranging from 1 to 100 on the backside being assigned to the different brightness levels on the front side of the scale. ${ }^{11}$ Facial size was determined by summating the distance resulted from two lines extended from corner of the mouth to the tragus of the ear and from the lateral canthus of the eye to the angle of the mandible. ${ }^{12}$ Subsequantly, comparing preoperative facial size values versus those collected postperatively was done at different time intervals of follow up either at the $2^{\text {nd }}$ and $7^{\text {th }}$ day.

\section{Measurement of mouth-opening ability}

Inter-incisal distance associated with maximum mouth-opening ability of the patient was recorded using graduated caliper. Incisal edge of both maxillary and mandibular central incisors were used as a reference point.

\section{Prognosis and score}

At the $7^{\text {th }}$ day, healing level was recorded either normal, delayed without infection, delay of granulation or formation of deep or severe infection and prognosis was ranked according to the previous categories into 4 points indicating the highest score for normal healing. ${ }^{13}$

\section{Neurosensory deficit}

Two-point discrimination-test was applied on lower lip for evaluation of presence or absence of sensation either at 7,15 and 30 days after surgery. ${ }^{10}$
A comprehensive questionnaire was used for recording Postoperative Symptom Severity (PoSSe) scale of all patients within this study at the $7^{\text {th }}$ postoperative day, including patient's ability to enjoy food, speak properly, perceive altered sensation, and their appearance, pain, sickness, and interference with daily activities. ${ }^{14,15}$

\section{Statistical Analysis}

Collected data was analyzed by SPSS (SPSS, Inc, Chicago, IL) program statistical package for social science version 16. Simple t test was used to compare both groups. Chi square test was used for qualitative data. $\mathrm{P}$ is significant if $<$ or $=0.05$ at confidence interval $95 \%$.

\section{RESULTS}

Eighteen patients 11 males and 7 females with an age ranging between 21 and 39 years with an average age of 27.22 years were included within this study and instructed to follow up during the $1^{\text {st }}$ postoperative week for assessment of pain, trismus, swelling, prognosis of healing and recording the (PoSSe) scale and after 15 and 30 days for further evaluation of occurrence of any neurosensory deficit.

\section{Clinical evaluation}

\section{I-Operation time}

The recorded average mean values of operation time for patients included in the $1^{\text {st }}$ group was $34.88 \pm 1.69 \mathrm{~min}$. However, it was $51 \pm 2 \mathrm{~min}$ for patients included in the $2^{\text {nd }}$ group. A clearly marked significant difference was recorded among both groups with regard to operation time $(\mathrm{P}=0.000)$ (Table 1).

\section{Postoperative pain \& inter-incisal distance as- sessment}

Patients included in this study revealed variable distribution of percentage of pain severity either at $48 \mathrm{~h}$, and 7 days of follow up. After 2 days, 
in $1^{\text {st }}$ group six patients were still symptomatic (VAS score $\geq 5$ ); three patients had improved (VAS score $\leq 5$ and $\geq 2$ ). Three patients were still symptomatic compared with six patients had improved in $2^{\text {nd }}$ group.

After 7 days, two patients were still symptomatic; three patients had improved, and four patients were pain free (VAS score $=0$ ) for those patients included in $1^{\text {st }}$ group. On the other hand, no patient was still symptomatic; five patients had improved, and four patients were pain free for those patients included in $2^{\text {nd }}$ group.

Comparing both groups, a statistical significant difference was recorded regarding to severity of pain using (VAS) at $48 \mathrm{~h}(\mathrm{P}=0.037)$. However, no significant difference was recorded regarding to severity of pain at $7^{\text {th }}$ day postoperatively $(\mathrm{P}=0.169)$ (Table 2)
In lingual split group, the inter-incisal distance (IID) recorded with an average mean values 12.22 $1.53 \mathrm{~mm}$ at 48 hours, and $26 \pm 1.73 \mathrm{~mm}$ in $7^{\text {th }}$ day postoperatively. However, in piezotome group, the inter-incisal distance (IID) recorded with an average mean values $14.55 \pm 1.23 \mathrm{~mm}$ at 48 hours, and $31.88 \pm 1.96 \mathrm{~mm}$ in $7^{\text {th }}$ day postoperatively.

A remarkable significant differences were recorded between both groups at the $2^{\text {nd }}$ and $7^{\text {th }}$ day of follow up $(\mathrm{P}=0.009-0.001$ respectively). A remarkable significant difference was recorded inside $1^{\text {st }}$ group when comparing IID values recorded after 7 days versus preoperative IID values for the same group $(\mathrm{P}=0.000)$. However, no significant difference was recorded inside $2^{\text {nd }}$ group when comparing IID values recorded after 7 days versus preoperative IID values for the same group $(\mathrm{P}=0.056)$ (Table 3)

TABLE (1) Showing mean, standard deviation \& level of significance between both groups regarding operation time

\begin{tabular}{|c|c|c|c|c|}
\hline Operation Time & Mean & Std. Deviation & Std. Error Mean & P value \\
\hline Lingual split Versus piezotome & 16.111 & 2.848 & .9493 & .000 \\
\hline
\end{tabular}

TABLE (2) Showing mean, standard deviation \& level of significance between both groups regarding to pain severity either at $2 \& 7$ days of follow up.

\begin{tabular}{|c|c|c|c|c|}
\hline Assessment of Pain severity & Mean & Std. Deviation & Std. Error Mean & P value \\
\hline Lingual split Versus piezotome after 2 days & 2.0000 & 2.3979 & .7993 & 0.037 \\
\hline Lingual split Versus piezotome after 7 days & .8888 & 1.7638 & .5879 & 0.169 \\
\hline
\end{tabular}

TABLE (3) Showing mean, standard deviation \& level of significance between both groups regarding to inter-incisal distance either at $2 \& 7$ days of follow up

\begin{tabular}{|c|c|c|c|c|}
\hline Assessment of Inter-incisal Distance IID & Mean & Std. Deviation & Std. Error Mean & P value \\
\hline IID Of lingual split Versus Piezotome after 2 days & 2.3333 & 2.0615 & .6871 & 0.009 \\
\hline IID Of lingual split Versus Piezotome after 7 days & 5.8888 & 3.5158 & 1.1719 & 0.001 \\
\hline
\end{tabular}




\section{Postoperative swelling}

In lingual split group, the distance from the corner of the mouth to the tragus of the ear was recorded with an average mean values $13.62 \pm 0.08 \mathrm{~mm}$ in $2^{\text {nd }}$ day, and $13.33 \pm 0.12 \mathrm{~mm}$ in $7^{\text {th }}$ day postoperatively. However, piezotome group showed an average mean values $13.46 \pm 0.11 \mathrm{~mm}$ after 48 hours, $13.15 \pm$ $0.088 \mathrm{~mm}$ after 7 days. While, in the $1^{\text {st }}$ group, the distance from the lateral canthus of the eye to the angle of the mandible showed an average mean values11.65 $\pm 0.11 \mathrm{~mm}$ after 48 hours, $11.21 \pm 0.1$ at $7^{\text {th }}$ day postoperatively. However, the $2^{\text {nd }}$ group showed an average mean values $11.24 \pm 0.15 \mathrm{~mm}$ after 48hours, $10.97 \pm 0.08$ in $7^{\text {th }}$ postoperative day.

Regarding to sum of measurements of facial size, no statistical significant difference was recorded preoperatively between both groups $(\mathrm{P}=0.849)$. However, a significant differences were established among both groups after 48 hours $(\mathrm{P}=0.005)$ and 7 days $(\mathrm{P}=0.001)$. In piezotome group, no significant difference was recorded between the sum of measurements of facial size recorded preoperatively and after 7 days $(\mathrm{P}=0.512)$ compared with high statistical significant differences in lingual split group for the same comparable time intervals $(\mathrm{P}=0.000)$ (Table 4).

\section{Prognosis}

After 7 days, three patients in the $1^{\text {st }}$ group scored grade 4 (normal healing), two patients showed delayed healing without infection compared with four patients revealed delayed granulation tissue formation. In $2^{\text {nd }}$ group, five patients scored grade 4 (normal healing), three patients showed delayed healing without infection compared with only one patient revealed delayed granulation tissue formation. No patient in both groups showed dry socket formation. Patients with grade 3 were managed just by follow up until healing completed. Furthermore, patients with delay of granulation, were managed with good curettage until fresh blood coming out then an obtundant dressing was applied and followed up. Regarding to prognosis of healing, no significant difference was recorded between both groups $(\mathrm{P}=0.061)$ (Table 5)

Regarding to assessment of two-point discrimination-test, a statistical significant differences were recorded between both groups after 7 and 15 days of follow up ( $\mathrm{p}=0.035)$. However, no statistical significant difference was recorded between both groups after 4weeks of follow up $(\mathrm{P}=0.169)$.

TABLE (4) Showing mean, standard deviation \& level of significance between both groups regarding to Sum of Facial size either at $2 \& 7$ days of follow up

\begin{tabular}{|c|c|c|c|c|}
\hline Assessment of Sum of Facial Size & Mean & Std. Deviation & $\begin{array}{c}\text { Std. Error } \\
\text { Mean }\end{array}$ & P value \\
\hline $\begin{array}{c}\text { Preoperative sum of facial size of lingual split versus } \\
\text { piezotome group }\end{array}$ & .0111 & .1691 & .0563 & 0.849 \\
\hline $\begin{array}{c}\text { Sum of facial size of lingual split group versus piezotome } \\
\text { group after 2days }\end{array}$ & .2666 & .2121 & .0707 & 0.005 \\
\hline $\begin{array}{c}\text { Sum of facial size of lingual split group versus piezotome } \\
\text { group after 7days }\end{array}$ & .4111 & .2204 & .0734 & 0.001 \\
\hline
\end{tabular}


TABLE (5) Showing level of significance between both groups regarding to prognosis assessment after 7 days.

\begin{tabular}{|c|c|c|c|}
\hline Prognosis scores & Value & Df & Asymp. Sig. (2-sided) \\
\hline Pearson Chi-Square & $9.000^{\mathrm{a}}$ & 4 & 0.061 \\
\hline
\end{tabular}

According to the Postoperative Symptom Severity (PoSSe) scale assessment among patients included in both groups, no statistical significant differences regarding to eating $(\mathrm{P}=0.347)$, speech $(\mathrm{P}=0.169)$, pain severity $(\mathrm{P}=0.169)$, sickness $(\mathrm{P}=0.258)$ and inerference with daily activity $(\mathrm{p}=0.347)$. However, remarkable significant differences were recorded between both group with regard to appearance $(\mathrm{P}=0.001)$ and level of sensation $(\mathrm{P}=0.035)$.

\section{DISCUSSION}

The most serious complications following surgical extractions of third molar represented in permanent nerve damage and fetal infections, but the rate of such complications is low. ${ }^{16-19}$ Fundmentally, success of such surgical procedures depends mainly on proper preoperative planning, resulted from additional training and experience..$^{3,18,19}$

Although, various sources have advocated piezosurgery for impacted mandibular third molar removal, sparse information has been provided on the optimal osteotomy method for different impaction types. ${ }^{20-26} \mathrm{In}$ addition to expense and the possibility of surgical tips breakage,$^{27}$ the other main disadvantage of Piezosurgery was basically reported in the increased operating time resulted from slow cutting rate.$^{28}$ However, minimizing the cutting times can be resulted with the improvement of the operator experience. ${ }^{29}$

It was believed that piezoelectric osteotomy techniques have a longer surgical time compared with rotatory osteotomy techniques. ${ }^{22-26}$ In accordance with aforementioned clinical studies, ${ }^{22-26}$ a remarkable significant difference was recorded among both groups of this study with regard to operation time $(\mathrm{P}=0.000)$. Furthermore, authors believed that operation time could be used as a basic indicator for extraction difficulty. ${ }^{1,30,31}$ Other studies reported that patients with operation time $\geq 30$ minutes had a prolonged recovery. ${ }^{32,33}$

According to Pedersen \& Oikarinen, the amount of analgesic consumption, trismus and pain level were significantly related to the duration of surgical operation. ${ }^{34,35}$ However, other authors declared that the postoperative sequelae was independent of the extent of the operating time. ${ }^{36}$ Our results showed that inter-incisal distance and sum of facial swelling revealed high statistical significant differences between both groups at the $2^{\text {nd }}$ and $7^{\text {th }}$ day of follow up $(\mathrm{P}=0.009,0.005-0.001,0.001$ respectively). Moreover, a significant difference was recorded regarding to severity of pain using (VAS) at $48 \mathrm{~h}(\mathrm{P}=0.037)$. However, no significant difference was recorded regarding to severity of pain at $7^{\text {th }}$ day postoperatively $(\mathrm{P}=0.169)$.

Such findings can be attributed to the minimum surface area that micrometric cut delivered from piezotome leading to the good results. Careful flap management might also explain our findings for pain, swelling, and trismus. The cutting selectivity of Piezosurgery that recognizes hardness of tissues and works only on mineralised structures represented the main advantage of Piezosurgery, so causes no damage to soft tissues. ${ }^{37}$

On the other hand, a established close relation between surgical experience and postoperative complication rate has been previously suggested, ${ }^{\mathbf{3 8 , 3 9}}$ whereas other studies have failed to show any 
relationship. ${ }^{36,40}$ Regarding such debate, all patients included in this study were treated by same operator and were selected from a common pool of same surgical difficulty divided into two equal uniform and harmoniously distributed groups.

Regarding to assessment of two-point discrimination-test, a statistical significant differences were recorded between both groups after 7 and 15 days of follow up ( $p=0.035)$. Such findings can be attributed initially to irrigating solution produced from oscillating tip which allows for better visibility minimizing the risk of nerve injury. Additionally, the role of cavitation phenomenon during evacuation of detritus and producing an implosion of gas bullae into blood vessels during bony cutting that results in a haemostatic effect and reduction of blood $\operatorname{loss}^{41}$ in the operating field. Such mechanism can minimize the risk of extra neuronal hematoma formation with their subsequent pressure on the lingual nerve. Moreover, during operation the Piezotome allows more easier tactile control and precision of cutting. ${ }^{42,43}$

According to a study of Horton et al. ${ }^{44}$ evaluating the impact of different bone cutting tools on postoperative wound healing, rotary burs were able to produce the most deleterious effect to the wound margins associated with subsequent delayed healing. On the other hand, chisel resulted in the best healing followed closely by ultrasonic instruments and lastly the bur. ${ }^{44}$ In agreement with Horton et al, our results revealed no significant difference among both groups with regard to prognosis of healing of surgical site $(\mathrm{P}=0.061)$.

Unfortunately, the major findings of this study revealed that piezosurgery is time consuming procedure when compared with conventional technique beside it is considered as a technique sensitive maneuver varied according to operator experience and device adoption which can not diminish the positive impact of piezosurgery as novel technique on the postoperative sequelae following surgical removal of impacted lower third molar especially, when compared with classic lingual split technique .

\section{CONCLUSION}

Although, a remarkable improvement in the postoperative sequelae associated with piezotome versus conventional lingual split bone technique. However, such technique sensitive maneuver related to operator experience and device adoption can lead to a significant prolonged operation time making a restrictive insult to achieve optimal clinical outcomes among oral surgeons.

\section{REFERENCES}

1- Renton T, Smeeton N, McGurk M. Factors predictive of difficulty of mandibular third molar surgery. Br Dent $\mathrm{J}$ 2001; 190:607-10.

2- Akadiri O A, Obiechina A E. Assessment of difficulty in third molar surgery: A systematic review. J Oral Maxillofac Surg 2009;67: 771-4.

3- Savin J, Ogden G R. Third molar surgery: A preliminary report on aspects affecting quality of life in the early postoperative period. Br J Oral Maxillofac Surg.1997; $35: 246$.

4- McGrath C, Comfort M B, Lo E C. Changes in life quality following third molar surgery: The immediate postoperative period. Br Dent J.2003; 194:265.

5- Absi J P, Shepherd. A comparison of morbidity following the removal of lower third molar by the lingual split and surgical burs methods. J oral Maxillofac Surg.1993;Jun 22(3):149-153.

6- Vercellotti, T. Essentials in piezosurgery: Clinical advantages in dentistry. 1st Edition, Quintessence Publishing Co., San Francisco, (2009).

7- Gleizal A, Béra J C, Lavandier B and Béziat J L. Piezoelectric osteotomy: A new technique for bone surgery: Advantages in craniofacial surgery. Child's Nervous System 2007; 5: 509-513.

8- Geha A H J, Gleizal A, Nimeskern $\mathrm{N}$ and Béziat J L. Sensitivity of the inferior lip and chin following mandibular bilateral sagittal split osteotomy using piezo-surgery. Plastic and Reconstructive Surgery.2006; 118: 1598-1607. 
9- Gleizal A, Li S L, Pialat J B and Béziat J L. Transcriptional expression of calvarial bone after treatment with lowintensity ultrasound: An in vitro study. Ultrasound in Medicine \& Biology.2006; 32: 1569-1574.

10- Troedhan A, Kurrek A, Wainwright M. Ultrasonic piezotome surgery: Is it a benefit for our patients and does it extend surgery time? A retrospective comparative study on the removal of 100 impacted mandibular 3rd molars. Open Journal of Stomatology, 2011; 1: 179-184.

11- Schmid-Schwap M, Bristela M, Kundi M, Piehslinger E. Treatment of patients with temporomandibular disorders: A retrospective treatment comparison. J Stomat Occ Med. 2009; 2: 59-64.

12- Griffin S O, Barker L K, Griffin P M, Cleveland J L, Kohn W. Oral health needs among adults in the United States with chronic diseases. J Am Dent Assoc. 2009;140:12661274 .

13- Kohji I, Tetsuo K, Yasunobu Y, Masashi K, Yukihiro O. Azithromycin as prophylaxis for the prevention of postoperative infection in impacted mandibular thirdmolar surgery. J Infect Chemother. 2006; 12:31-35.

14- Grossi G B, Maiorana C, Garromone R A, Borgonovo A, Farronato D. Effect of submucosal injection of dexamethasone on postoperative discomfort after third molar surgery: A prospective study. J Oral Maxillofac Surg $2007 ; 65: 2218-26$.

15- Ruta D A, Bissias E, Ongston S, Ogden G R. Assessing health outcomes after extraction of third molars: The postoperative symptom severity (PoSSe) scale. BrJ Oral Maxillofac Surg 2000; 38:480-7.

16- Valmaseda-Castellón E, Berini-Aytés L, Gay-Escoda C. Inferior alveolar nerve damage after lower third molar surgical extraction: A prospective study of 1117 surgical extractions. Oral Surg Oral Med Oral Pathol Oral Radiol Endod.2001; 92:377.

17- Renton T, McGurk M. Evaluation of factors predictive of lingual nerve injury in third molar surgery. Br J Oral Maxillofac Surg.2001; 39:423.

18- Goldberg M H, Nemarich A N, Marco W P. Complications after mandibular third molar surgery: A statistical analysis of 500 consecutive procedures in private practice. J Am Dent Assoc.1985;111:277.

19- Indresano A T, Haug R H, Hoffman M J. The third molar as a cause of deep space infections. J Oral Maxillofac Surg.1992; 50:33.
20- Pippi R, Alvaro R. Piezosurgery for the lingual split technique in mandibular third molar removal: A suggestion. J Craniofac Surg.2013; 24:531.

21- Eggers G, Klien J, Blank J. Piezosurgery: An ultrasound device for cutting bone and its use and limitations in maxillofacial surgery. Br J Oral Maxillofac Surg.2004; 42:451.

22- Rullo R, Addabbo F, Papaccio G. Piezoelectric device vs. conventional rotative instruments in impacted third molar surgery: Relationships between surgical difficulty and postoperative pain with histological evaluations. J Craniomaxillofac Surg 2013; 41:e33.

23- Sortino F, Pedulla E, Masoli V. The piezoelectric and rotatory osteotomy technique in impacted third molar surgery: Comparison of postoperative recovery. J Oral Maxillofac Surg. 2008; 66:2444.

24- Goyal M, Marya K, Jhamb A. Comparative evaluation of surgical outcome after removal of impacted mandibular third molars using a Piezotome or a conventional handpiece: A prospective study. Br J Oral Maxillofac Surg. 2012; 50:556.

25- Barone A, Marconcini S, Giacomelli L. A randomized clinical evaluation of ultrasound bone surgery versus traditional rotary instruments in lower third molar extraction. J Oral Maxillofac Surg.2010; 68:330.

26- Bartuli F N, Luciani F, Caddeo F. Piezosurgery vs high speed rotary handpiece: A comparison between the two techniques in the impacted third molar surgery. Oral Implantol.2103; 6(1):5-10.

27- Gonzalez-Garcia A, Diniz-Freitas M, Somoza-Martin M, Garcia- Garcia A. Ultrasonic osteotomy in oral surgery and implantology. Oral Surg Oral Med Oral Pathol Oral Radiol Endod 2009;108:360-7.

28- Crosetti E, Battiston B, Succo G. Piezosurgery in head and neck oncological and reconstructive surgery: Personal experience on 127 cases. Acta Otorhinolaryngol Ital 2009; 29:1-9.

29- Beziat J L, Bera J C, Levandier B, Gleizal A. Ultrasonic osteotomy as a new technique in craniomaxillofacial surgery. Int J Oral Maxillofac Surg. 2007; 36:493-500.

30- Susarla S M, Dodson T B. Risk factors for third molar extraction difficulty. J Oral Maxillofac Surg.2004; 62:1363.

31- Santamaria J, Arteagoitia I. Radiologic variables of clinical significance in the extraction of impacted mandibular third molars. Oral Surg Oral Med Oral Pathol.1997; 84:469. 
32- Conrad S M, Blakey G H, Shugars D A. Patients' perception of recovery after third molar surgery. J Oral Maxillofac Surg.1999; 57:1288.

33- Phillips C, White R P, Shugars D A. Risk factors associated with prolonged recovery and delayed healing after third molar surgery. J Oral Maxillofac Surg.2003; 61:1436.

34- Anne Pedersen. Inter-relations of complaints after removal of impacted mandibular third molars. Int J. Oral Surg. 1985; 14: 241-244.

35- Oikarinen K. Postoperative pain after mandibular thirdmolar surgery. Acta Odontol Scand 1991; 49:7-13.

36- Benediktsdòttir I S, Wenzel A, Petersen J K. Mandibular third molar removal: Risk indicators for extended operation time, postoperative pain, and complications. Oral Surg Oral Med Oral Pathol Oral Radiol Oral Endod. 2004; 97:438.

37- RobionyM, Polini F, Costa F, Vercellotti T, Politi N. Piezoelectric bone cutting in multipiece maxillary osteotomies. J Oral Maxillofac Surg. 2004; 62:759-61.

38- Capuzzi P, Montebugnoli L, Vaccaro M A. Extraction of impacted third molars. A longitudinal prospective study on factors that affect postoperative recovery. Oral Surg Oral Med Oral Pathol.1994;77:341.

39- De Boer M P J, Raghoebar G M, Stegenga B. Complications after mandibular third molar extraction. Quintessence Int.1995; 26: 779 .

40- Oginni F O, Fatusi O A, Alagbe A O. A clinical evaluation of dry socket in a Nigerian teaching hospital. J Oral Maxillofac Surg.2003; 61:871.

41- Leclercq P, Zenati C, Amrand S, Dohan D M. Ultrasonic bone cut Part 1: State-of-the-art technologies and common applications. J Oral Maxillofac Surg 2008; 66:177-82.

42- Garg A K. Using the Piezosurgery device: Basics and possibilities. Dent Implantol Update 2007; 18:1-4.

43- Gruber R M, Kramer F J, Merten H A. Ultrasonic surgery: An alternative way in orthognathic surgery of the mandible. A pilot study. Int J Oral Maxillofac Surg. 2005;34:590.

44- Horton J E, Tarpley T M J, Wood L D. The healing of surgical defects in alveolar bone produced with ultrasonic instrumentation, chisel and rotary bur. Oral Surgery, Oral Medicine, Oral Pathology, Oral Radiology, and Endodontology. 1975;39: 536-546. 